ORIGINAL RESEARCH ARTICLE

\title{
Exploring the Causes of Change in Adolescent Girls' Sexual Behaviour in Begoro, Ghana
}

\author{
Sylvia E. Gyan \\ University of Ghana, Department of Sociology \\ *For Correspondence: Email: sgyan@ug.edu.gh
}

\begin{abstract}
There is a changing trend in adolescent girls' sexual and reproductive behaviour in Ghana. However, contemporary perspectives on adolescent girls' sexual behaviours are largely missing hence this study. Thematic analysis of data collected through in-depth interviews with adolescent girls and community members as well as focus group discussions with adolescent boys identified several factors accounting for the changes in adolescent girls' sexual and reproductive behaviour. These factors include changes in girls' attitudes to traditional practices, diversity in the agents of socialization as well as the age at menarche. This has resulted in a clash of value system between girls' sexual behaviours and that of the elderly. Thus, the social context in which girls are experiencing sexual and reproductive life in Ghana is changing and this must be taken into consideration when designing any intervention to help adolescent girls become resilient in their sexual and reproductive lives. (Afr J Reprod Health 2017; 21[2]: 55-63).
\end{abstract}

Keywords: adolescent girls, sexual behaviour, social change, Ghana

\section{Résumé}

Il existe une tendance à l'évolution des comportements sexuels et de la reproduction chez les adolescentes au Ghana. Cependant, les perspectives contemporaines sur les comportements sexuels des adolescentes sont en grande partie manquantes, d'où cette étude. L'analyse thématique des données recueillies grâce à des entretiens approfondis avec des adolescentes et des membres de la communauté, ainsi que des discussions de groupes cibles avec des garçons adolescents ont identifié plusieurs facteurs qui expliquent les changements dans les comportements sexuels et de la reproduction chez les adolescentes. Ces facteurs incluaient des changements dans l'attitude des filles à l'égard des pratiques traditionnelles, la diversité chez les agents de la socialisation ainsi que l'âge de la ménarche. Cela a entraîné un choc de système de valeurs entre les comportements sexuels des filles et celui des personnes âgées. Ainsi, le contexte social dans lequel les filles connaissent une vie sexuelle et de la reproduction au Ghana évolue et cela doit être pris en compte lors de la conception d'une intervention pour aider les adolescentes à devenir résilientes dans leur vie sexuelle et de la reproduction. (Afr J Reprod Health 2017; 21 [2]: 55-63).

Mots clés: adolescentes, comportement sexuel, changement social, Ghana

\section{Introduction}

The population of adolescents is estimated to be more than one billion in the world, with about $70 \%$ living in developing countries ${ }^{1,2}$. Studies of developing countries have shown that adolescents initiate sex and experience sex before marriage ${ }^{2,3}$. The Ghana Demographic Health Survey (GDHS $2014)^{4}$ reports the median age at first sex for women aged 25-49 as 18.8 years in the urban areas and 17.8 years in the rural areas ${ }^{4,5}$. However, other studies in specific regions of Ghana found the median age at first sex to be 15 years ${ }^{6,7}$. This notwithstanding, the mean age of first marriage in rural Ghana is 20.9 years for females and 24.9 years for their male counterparts among people between the ages of 20-24 years ${ }^{4}$. The data indicates that the age at which adolescents experience their first sexual intercourse does not tally with the age at first marriage, suggesting that most adolescent girls experience sex out of wedlock. The changing trend where adolescent girls are postponing age at marriage has been attributed to formal education and the changing values and norms on the appropriate age for marriage ${ }^{8,9}$.

In the past, adolescents in Africa were initiated from childhood to adulthood when they 
reached puberty. In East Africa, specifically among the Banda in Uganda, girls were initiated by their paternal aunties (Ssengas) who tutored them on a wide range of sexual matters including premenarche practices, pre-marriage preparation, erotic instruction and reproduction ${ }^{10}$. However, in recent times, the work of Ssengas has been taken over by people who have now commercialized the entire process.

In Ghana, traditionally, the stage of adolescence among most ethnic groups begins with the on-set of 'menarche' for girls. Most ethnic groups in Ghana mark this stage with the performance of puberty rites for the adolescent girls ${ }^{11,13}$. The traditional practice was that before a girl could go through this rite of passage, she must be a virgin ${ }^{11,14}$. Therefore, in the pre-colonial period, girls who became pregnant before going through the puberty rites were severely punished in the form of banishment from the community ${ }^{11,14,15}$.

Girls were taken through puberty rites to usher them into womanhood ${ }^{13}$. The common initiation rites for girls were 'Bragoro' among the Akan ethnic groups and 'Dipo' among the Krobo. During such initiation rites, girls were secluded for days or weeks where they were taught the secrets of womanhood such as how to be good wives, lessons about their sexuality and how to be caretakers of their future marital homes ${ }^{11,13}$. The initiation rites usually ended with a durbar where the initiated girls are paraded through the town in rich cloths and beads to announce their readiness to get married. Parading girls on the streets after going through the puberty rites helped them to attract potential suitors ${ }^{11}$. These initiation rites could therefore be said to be ceremonies that prepared girls for marriage. Traditionally, marriage and childbearing closely followed puberty among most ethnic groups in Ghana and first sex was expected to take place largely within marriage? This traditional practice therefore contributed to the low incidence of out of wedlock sex and pregnancy.

The social environment in which adolescents experience sex, pregnancy and motherhood has undergone some changes due to the increasing rates of migration, rise in enrolment in schools and the dominance of Muslim and Christian religions over the traditional value systems ${ }^{8,9,16,17}$. With increasing urbanization, migration and formal education, adolescent girls tend to experience a long gap between menarche and marriage, which increases their likelihood to engage in sex before marriage. It has been observed that adolescents are confronted by four value systems of socialization with their associated normative behaviour ${ }^{18}$. Adolescents are confronted with traditional and religious value systems which cherish virginity among adolescent girls and young people are expected to have sex only within marriage ${ }^{13,18-20}$. On the other hand, they are confronted by a modern legal value system, which gives the age for marriage as 18 years, and a value system which emphasizes romantic ideas of friendship and love ${ }^{9,18}$. Thus, the traditional system in which adolescent girls are socialized with values and norms that uphold sexual intercourse and childbearing as acceptable only within marriage now competes with three other (modern) values as identified by Ahlberg $^{18}$. These traditional and modern value systems operate side by side and create tension and confusion as to the most appropriate sexual behaviour among adolescent girls ${ }^{18}$. The tension created by the different values can predispose adolescent girls to unsafe sexual and reproductive practices in their attempt to meet the society's 'appropriate' sexual behaviour ${ }^{13,20}$. Despite a traditional value system that upholds chastity before marriage, substantial proportions (37\%) of adolescent girls in Ghana engage in premarital $\operatorname{sex}^{4}$. With these challenges facing adolescent girls in mind, this article identifies and discusses the contemporary factors responsible for changes in adolescent sexual and reproductive behaviours and their effects, to provide some insights into how the changing social context is influencing the sexual behaviours of adolescent girls in Begoro, Ghana.

\section{Research site}

The study was conducted in Begoro, the district capital of Fanteakwa, which is one of the twenty one (21) districts within the Eastern Region of Ghana. The Eastern Region of Ghana has one of 
the highest teenage pregnancy rates $(16 \%)$ in the country $^{21}$. The population of Begoro is varied in terms of ethnicity; there are six ethnic groups with the Akans dominating, followed by the GaAdangmes. These two dominant ethnic groups provide typical examples of the ethnic groups in Ghana that perform customary rites for girls when they reach puberty. The Akans have the 'Bragoro' and Ga Adangmes the 'Dipo'. However, with the increasing dominance of Christianity (86.3\%) and Islam (11.2\%) in the community, there has been a decline in the participation of girls in these customary rights ${ }^{22}$.

\section{Methods}

The paper is part of a larger study that used the mixed method approach to collect and analyse data on how adolescent girls are able to adjust or avoid the risk they may be predisposed to in their sexual and reproductive life. However, this paper focuses only on the qualitative data. Purposive sampling was used to select fifty-four participants in the qualitative study, which comprised 20 adolescent girls, 12 elderly community members and 22 adolescent boys. Three distinct interview guides were used to collect data for the study. One was used to collect data from adolescent girls and another for the views of adult community members about the changes in adolescent girls' sexual and reproductive behaviour. The third served as a guide during the focus group discussion on the themes identified in the interviews. The interview guides were pretested to ensure the questions solicited for the answers the research was seeking. All the interviews and discussions were audio-recorded and initially transcribed and translated from the local language (Twi/Ga) into English. The transcriptions were diligently read, reflecting on the information and identifying topical issues from them. The various themes that emerged from the transcribed data were identified and coded. The various themes were used as a guide for selecting appropriate texts for the analysis.

\section{Results}

\section{Changes in agents of socialization}

Social change has led to changes and additions to the agents of socialization on adolescent sexual and reproductive health. Almost all participants indicated that the agents involved in the socialization of adolescent girls on their sexuality are changing. The educational system offers opportunities for adolescent girls to learn about their sexuality and manage their sexual experience as stated in the following narrative:

They (teachers) teach us those things (sexual and reproductive health) at school. The teachers teach us how to use condoms to protect ourselves and how to access family planning. They also teach us that we can buy medicine at the pharmacy shop to prevent pregnancy

(Adwoa, an Adolescent Girl, In-depth interview, Begoro)

The other participants hold similar views and this has been well summarised in the views expressed in the narrative below:

Things have changed... because of the girl child education. Some years ago, the teenagers did not know how to avoid pregnancy, but now with the introduction of the family planning methods they can protect themselves (Man 3).

The above response reveals how formal education is perceived to influence adolescents' sexual behaviour.

Other sources identified as providing adolescent girls with sexual and reproductive health education include the radio and hospitals. An adolescent girl notes:

I know that you can use pills and condoms to protect yourself, some people go for injections ... it is really helping me, 
without that I would have had a baby by now

(Asor, an Adolescent Girl, In-depth interview, Begoro)

This was corroborated by a female participant who said that:

They (radio programmes) teach them (adolescents) on how to protect themselves from teenage pregnancy when they have sex, on the radio and at the hospital but the "stubborn" ones do not listen, so it is never going to stop. Some do (listen) others do not even care all they do is to enjoy having sex... They (adolescent girls) get the knowledge from the clinic where they are advised to use family planning methods...." (Woman 6).

However, despite identifying the health facility as one of the sources adolescents receive support on sexual and reproductive health matters, most adolescent girls do not access it and this is captured in the narrative below:

... some don't even go for the family planning; they feel shy to go to the hospital (Woman 6).

It was observed that some adolescent girls who used contraceptives in their sexual activities for fear of being 'labelled' negatively sometimes travelled to the next town to access contraceptives instead of buying them in their own communities. Obaa Yaa explains:

People do not really know me well so when you even say something bad about me people will not believe it.... I usually buy the pills from Obuasi ' [Obaa Yaa from the interview indicated that she uses the emergency pill after having sex]

Obaa Yaa, an Adolescent Girl, In-depth interview, Begoro)

This suggests that although change is taking place, the traditional value of abstinence from sex until marriage persists and therefore girls tend to shy away from openly accessing family planning healthcare.

\section{Change in behaviour and attitudes of girls to traditional practices}

A common view held by the elderly that repeatedly came up throughout the in-depth interviews was adolescent girls' lack of respect for both their parents and the elderly in the community. The phrase that most community members typically used to explain the observed changes in adolescent girls' sexual behaviours and the factors responsible for the rise in teenage pregnancy in the community was

"Most of them (adolescent girls) don't respect ...".

According to an elderly woman:

The teenagers do not respect, they do not listen to the advice of their parents. What happens is that, they do not listen to advice and then they get pregnant, because you cannot disown them, they deliver (Woman $3)$.

However, in line with current trends, most adolescent girls explain that they receive information and knowledge about their sexuality from other sources such as the print and electronic media, teachers and books, which they consider to be enough to empower them to deal with their sexuality. This is represented in the following statement:

I watch television or listen to the radio, and they teach on these things (sex and teenage pregnancy). ... However, the radio is the one that really helps me. They (radio) have programmes that talk about these things, for example, someone may be pregnant, the man does not want to accept it, and they discuss it

(Akosua, an Adolescent Girl, In-depth interview, Begoro) 
Gyan

With girls having several sources of information about their sexuality, there is no doubt that their reliance on the traditional agents of socialization such as mothers and elderly women in society would continue to decline or diminish.

The elderly community members observed that the traditional way of socializing adolescent girls on the norms and values regarding their sexual behaviours have not changed, but rather it is the attitudes of girls that have changed. Some respondents expressed:

... Nowadays when the girls get to puberty, they do not tell their parents (Woman 6).

... When they have their first menstruation, they just go and buy pads (sanitary pads) but at first, they would report to their parents who would then use the opportunity to teach them about the change in their reproductive life after having their "period" (Man 4).

... This practice (puberty rites) has not changed in recent times, rather it is the youth that do not listen to the advice they (old women and parents) give them (Woman 1).

Adolescent girls no longer feel obliged to inform their mothers about the onset of menarche because they have knowledge on what to do when they menstruate. These views suggest a lack of communication between adolescent girls and their mothers about the onset of menarche, which was not the case in the past.

\section{Changes in the traditional values on sex}

The traditional practice of abstinence from sex before marriage and the acceptance of child bearing only in marriage are undergoing changes in the community. This is clearly represented by an elderly respondent in the following statement:

...If they (adolescent girls) are around seventeen years, you can advise them
Adolescent Girls' Changing Sexual Behaviour

(adolescent girls) to stay away from men or they should buy drugs to protect themselves from pregnancy. ...but some of the girls complain that they do not like the family planning drugs (Woman 5).

From the in-depth interviews, it was also found that some parents, for fear of their daughters becoming pregnant, now take the initiative to enrol their daughters on family planning programmes. An adolescent boy shares his sentiments on this:

I know of one or two families who encourage their daughters to go for family planning and some have even enrolled their daughters in family planning programmes at the district hospital (Boy 2).

Similarly, a man recounts his experience:

I know some parents who have done it (family planning) for their children because they know that they cannot keep their children from going out with men. They have something they put on their hand [Norplant] and that is what I know. ... one of the women told me she had done family planning for her daughter and she wanted me to check if the date for renewal was due since it had a three months' interval (Man 1).

With the increasing rate of out of wedlock pregnancy among adolescents, most respondents expressed the need to emphasize both abstinence and the use of contraceptives and other family planning methods among adolescents to avoid pregnancy outside of marriage.

\section{Changes in values pertaining to adolescent childbearing}

Although, respondents shared similar views on the acceptable age for a girl to start childbearing in Begoro, they also observed that there was no culturally defined age for childbearing in the community. According to one adult respondent: 
Gyan

... the right age for a girl to give birth is age twenty... because at that age she will be matured enough to take care of a child, at eighteen or fifteen years a person cannot do that, that's why we advise that twenty is the best age to give birth (Woman 4).

Generally, respondents were of the view that, the appropriate age for marrying and giving birth should be between the ages of 20 to 25 years. One woman noted:

... about twenty years, because by the age of fifteen they would have menstruated so if they wait for five more years, that will be okay, at that age they will be matured and they will be working so they can take care of their babies, they can buy their clothes and other things they need (Woman 3).

According to another woman:

The appropriate age that girls can give birth is around age twenty ...that will be okay, by that age they would have finished with their secondary school education (Woman 6).

The responsibilities that come with childbirth notwithstanding, some adolescent girls who had babies continued their education as captured in the narratives below:

By God's grace after having my baby, I am back in school and next year my baby will start schooling... so people praise me because most teenage mothers do not continue with schooling after giving birth

(Boatemaa, an Adolescent Girl, In-depth interview, Begoro).

I make sure that I take my academic work seriously to secure my future ... because if I drop out of school, people will say that after I had the baby I was not able to continue with my schooling. Now, people use me as an example to advice their children, they tell them of how I have been
Adolescent Girls' Changing Sexual Behaviour

able to continue with my school after giving birth

(Sheila, an Adolescent Girl, In-depth interview, Begoro)

It must however, be noted that in Ghana, the educational system tends to encourage girls to return to school after childbirth and there is a law against discrimination because of motherhood.

\section{Change in age at menarche}

Some respondents opined that the changing trend in adolescent sexual and reproductive experience in Begoro can be attributed to biological factors. There has been change in the age at which girls experienced menarche. More and more adolescents are experiencing menarche at earlier ages in contemporary times as compared to the traditional era.

A female respondent indicated that:

"now people give birth before the age of sixteen, but at first, you even reached puberty around age sixteen" (Woman 4).

This assertion by the respondents corroborates earlier studies, which suggest that early sexual and reproductive maturity is associated with risky sexual behaviours among adolescent girls ${ }^{23}$.

\section{Discussion}

The emergence of new social actors in the socialization of adolescents' sexual and reproductive health is identified as a contributing factor to the change in adolescent girls' sexual behaviour in Begoro, Ghana. The traditional institution where parents and elderly women played a role in the sexual education of children has been largely taken over by new social actors such as teachers (through the formal educational system), the media, and the health sector. With the incorporation of sexual and reproductive health education in the school syllabi, it is perceived that some adolescents now receive and rely more on what they are taught in school than totally relying 
on their parents, as was the case previously ${ }^{3,9,16}$. Additionally, the adolescent girls and the elderly in the community identified the hospital and the electronic media (radio) as other sources of information on sexual and reproductive health for girls in the community. These other actors such as the doctors and nurses at the hospital, teach and advice adolescents on their sexual and reproductive health in the community. Thus, the elderly in the community regard the refusal of adolescent girls to seek advice on sexual and reproductive health from them, as it used to be in the past, as a sign of disrespect. This behaviour must be put in the context where, unlike in the past, adolescent girls now have access to information on their sexual and reproductive health from sources other than their parents and the elderly members in their community. This suggests that the change in adolescent girls' attitude to advice from elderly persons including their parents is largely due to the broadening of the media landscape in Ghana. This has led to a clash of the value systems of adolescents, who are making use of modern technology, especially the media to gain information on their sexuality and its related behaviours, while the elderly continue to expect adolescent girls to pay attention to their advice on sexual behaviours.

Adolescent girls' behaviour of not informing their parents about the onset of menarche has been attributed to shyness ${ }^{3}$. This is however, not the case in Begoro since the lack of communication between adolescents and their parents is perceived as disrespect for the elderly in the community by the adolescents. The change in behaviour and attitude of adolescent girls has affected the traditional practice of taking them through puberty rites to be taught by older women and their mothers about their sexuality. Therefore, the apparent disinterest in the observance of the traditional practices of puberty rites and sexual education among adolescent girls is due to the lack of communication between adolescent girls and the elderly including mothers.

The traditional value of abstinence from sex until marriage is now giving way to the admonition that 'if you cannot abstain from sex, then use contraceptives or access family planning' in
Begoro. This should be seen in the light of generalised sex educational programs in the media and in schools, especially in the context of HIV/AIDS education. This has led to what could be referred to as the duality of value of abstinence or protection (condom/family planning). This reiterates the observations made by Ahlberg ${ }^{18}$ that adolescents encounter four value systems that are not mutually exclusive but exist side by side depending on their social context. Our findings suggest that adolescents seem to be influenced more by the different values regulating and shaping their sexual and reproductive lives and thus may sometimes find themselves in a dilemma as to which value system to adhere to.

Culturally there is no specified age for child bearing, however, in this study; there was consensus on the age of at least 18 years among the elderly respondents as the preferred age at which girls could have children. Their reasons for accepting eighteen years and above had to do with the maturity of a girl to have a baby, completion of higher education (at least senior high school), and her ability to earn income. This is similar to the findings reported by Adomako Ampofo ${ }^{13}$ where childbirth was viewed as an additional responsibility requiring that a person should be working in order to meet the financial demands that comes with having a child. The choice of 18 years and above as the appropriate age for a girl to start child bearing, is in line with the legal age (18 years) for marriage as stated in the 1992 constitution of Ghana.

There was a perception that adolescents in contemporary times tend to experience early onset of menarche a factor that seems to predispose them to sexual and reproductive health risk. Gollenberg et $\mathrm{al}^{24}$. in their study attributed the change in the timing of the onset of menarche to nutrition and chemical intake. The early onset of menarche is perceived as a factor that increases the likelihood of adolescent girls becoming pregnant when they engage in early sexual activities.

\section{Conclusion}

Findings discussed in this paper indicate that the social context of adolescent girls' sexual and 
reproductive experiences is changing, which could be both a blessing and a ban on the sexual behaviour of adolescent girls. Adolescent girls in Begoro now live in an environment where they have diverse information sources on how to avoid and adjust to the challenges that come with their sexual experiences. As noted by Bankole and his colleagues, these challenges range from their families, schools, communities, to the health centres within their community ${ }^{15}$. Although adolescent girls have diverse sources of information and education on sexual and reproductive health, "'it is not all of them" who are able to utilise these resources in their sexual and reproductive lives effectively. This has led to a perception by the elderly respondents that the diversity of information available has exposed girls to risky sexual behaviours, in that they promote adolescents' exposure to early sexual activities leading to teenage pregnancy and early motherhood. Our findings also support the view that changes in the social actors involved in adolescent sexual and reproductive health education has created tension between the traditional values of the society and the so called modern sexual behaviour of adolescent girls which is largely influenced by the media. Girls are confronted with societal and familial values of chastity and at the same time their own romantic values and the emerging national value, which involves the use of contraceptives ${ }^{18,20}$.

\section{Acknowledgements}

National Centre of Competence in Research (NCCR) North-South for funding the study.

Commonwealth Scholarship Commission for funding my one-year study abroad at the University of Sussex, UK during my PhD.

\section{References}

1. United Nations Population Fund. Generation of change: young people and culture, 2008, youth supplement to UNFPA's state of the world population report, New York: UNFPA, 2008.

2. Hindin M J and Fatusi AO. Adolescent sexual and reproductive health in developing countries. International Perspective on Sexual and Reproductive Health 2009; 35(2): 58 - 62 .

3. Henry R and Fayorsey C. Coping with pregnancy: experiences of adolescents in Ga Mashi, Accra Calverton, Maryland, USA: ORC Macro, 2002,1921

4. Ghana Demographic and Health Survey. Ghana Statistical Service. Accra, Ghana, 2014.

5. Ghana Statistical Service. 2010 Population and Housing Census of Ghana. Accra, Ghana, 2013.

6. Agyei WKA, Biritwum RB, Ashitey AG and Hill RB. Sexual behaviour and contraception among unmarried adolescents and young adults in Greater Accra and Eastern regions of Ghana. Journal of Biosocial Science 2000; 32, 495-512.

7. Nabila JS and Fayorsey CK. Adolescent fertility and reproductive behaviour in Ghana. in ArdayfioShandorf, E. (Ed.), The Changing Family in Ghana Accra. Ghana University Press, Accraa,Ghana, 1996.

8. Glover EK, Bannerman A, Pence BW, Jones H, Miller R, Weiss E. and Nerquaye-Tetteh J. Sexual health experiences of adolescents in three Ghanaian towns. International Family Planning Perspectives 2003; 29(1): 32-40.

9. Awusabo-Asare K, Abane A and Kumi-Kyereme A. Adolescent sexual and reproductive health in Ghana: a synthesis of research evidence. Occasional Report No. 13. The Alan Guttmacher Institute New York, USA, 2004.

10. Tamale $S$. The right to culture and the culture of rights: a critical perspective on women's sexual rights in Africa. Feminist Legal Studies, 2008; 16, 47-69.

11. Sarpong PK. Ashanti nubility rites. Ghana Publishing Corporation, Tema, Ghana, 1977.

12. Nukunya GK. Tradition and Change in Ghana: An Introduction to Sociology. Ghana University Press, Accra, 2003.

13. Adomako-Ampofo AA (2001). When men speak women listen: gender socialization and young adolescents' attitudes to sexual and reproductive health issues. African Journal of Reproductive Health 2001; 5(3), 196-212.

14. Steegstra M. A mighty obstacle to the gospel: Basel missionaries, Krobo women, and conflicting ideas of gender and sexuality. Journal of Religion in Africa 2002; 32 (2), 200-230.

15. Bleek W. Avoiding Shame: 'The ethical context of abortion in Ghana'. Anthropological Quarterly 1981; 54 (4), 203-209.

16. Biddlecom A, Gregory R, Lloyd CB and Mensch BS. Associations between premarital sex and leaving school in four sub-Saharan African countries. Stud Fam Plann 2008; 39 (4), 337-350.

17. Addai I. Religious affiliation and sexual initiation among Ghanaian women. Review of Religious Research 
2000; 41 (3), 328-343.

18. Ahlberg BM. Is there a distinct African sexuality? A critical response to Caldwell. Africa 1994; 64 (2), 220-242.

19. Marston C and King E. Factors that shape young people's sexual behaviour: a systematic review. Lancet 2006; $368,1581-1586$.

20. East L, Jackson D, O’Brien L. and Peters K. Condom negotiation: experiences of sexually active young women. Journal of Advanced Nursing, 2011; 67 (1), 77-85.

21. Ghana Statistical Service, Ghana Health Service and Macro International. Ghana Maternal Health Survey 2007. Calverton, Maryland, USA: GSS, GHS, and Macro International Inc. 2009; 73-89.

22. Ghana Statistical Service. 2010 Population and Housing Census of Ghana. Accra, Ghana, 2013.
23. Dunbar J, Sheeder J, Lezotte D, Dabelea D and StevensSimon C. Age at menarche and first pregnancy among psychosocially at-risk adolescents. American Journal of Public Health 2008; 98 (10), $1822-1824$.

24. Gollenberg AL, Hediger ML, Lee PA, Himes JH and Louis GMB. Association between Lead and Cadmium and Reproductive Hormones in Peripubertal U.S. Girls. Environ Health Perspect 2010; 118, 1782-1787.

25. Bankole A, Biddlecom A, Guiella G, Singh S and Zulu E. Sexual Behaviour, Knowledge and Information Sources of Very Young Adolescents in Four SubSaharan African Countries. African Journal of Reproductive Health 2007; 11(3), 28-43. 